\title{
The Right Little Fingerprint of Rev. Dr. Martin Luther King, Jr.
}

\author{
Andrés J Washington* \\ Fingerprint Geometric Analysis, Bronx, USA
}

*Corresponding author: Andrés J Washington, Fingerprint Geometric Analysis, Post Office Box 165, Bronx, NY 10451-0165, USA.

To Cite This Article: Andrés J Washington, The Right Little Fingerprint of Rev. Dr. Martin Luther King, Jr. Am J Biomed Sci \& Res. 2020 - 7(2). AJBSR. MS.ID.001129. DOI: 10.34297/AJBSR.2020.07.001129.

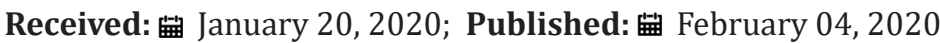

Abstract

In the frequency of NCIC FPC patterns, there is a range in the spectrum. The populous direction is one percent or greater. Anything less than one present is on the other side in the series. We must note the infinite regions of both sides of the confines. When a pattern falls in the million frequency or greater of less than one percent, it is in a category for further scrutiny. In as much as the brain and fingerprints develop simultaneously, we have a comparison between the thought processes of those from each side of the scale between two extreme or opposite points. Individuals on the unpopulous side of the spectrum may display dermal ridge arrangements reflecting a different time in the evolution of fingerprint patterns. As such, their natural thinking may be different from those of the populous direction (Figure 1).

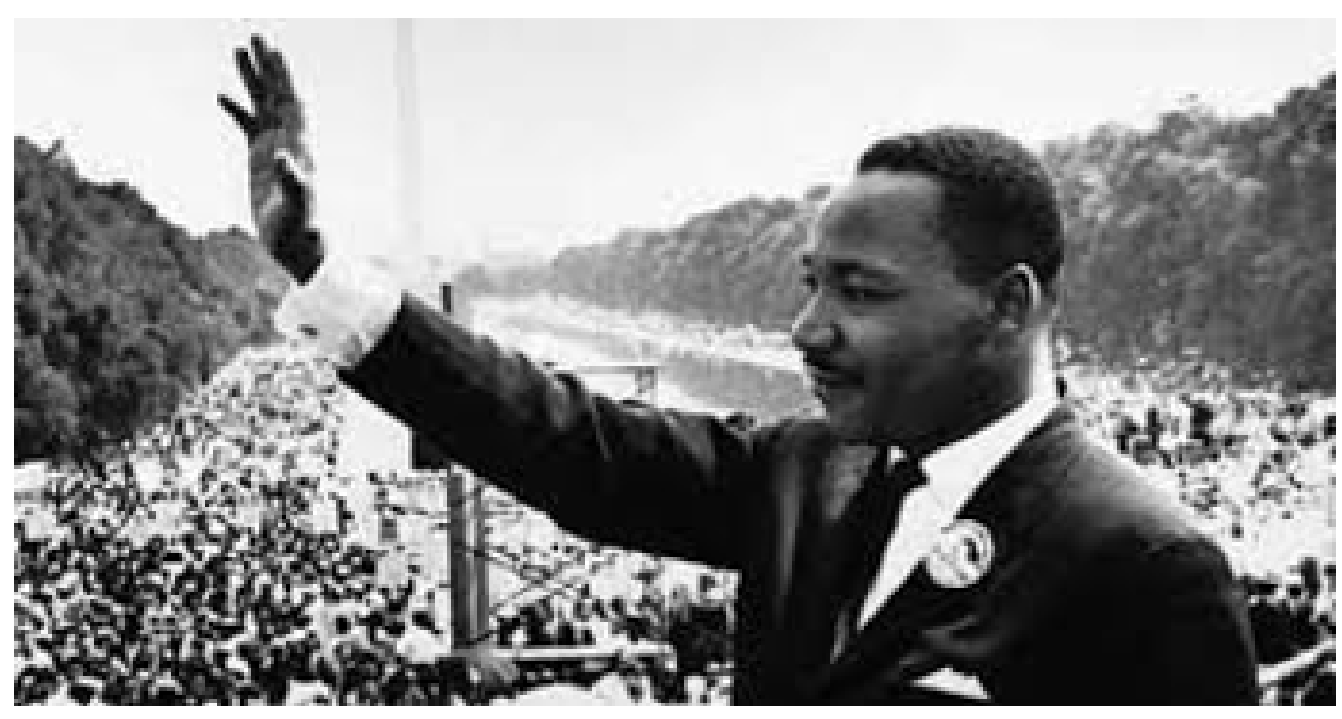

Figure 1.

Keywords: Dr. MLK, Jr Tented Arch; Fingerprint, Left Little; NCIC FPC Frequency

\section{Introduction}

The right little fingerprint of Rev. Dr. Martin Luther King, Jr. receives the classification of a tented arch pattern. As a pattern, it cannot classify simply as an ulnar loop or radial loop. Dr. King's

right little fingerprint is a combination of both radial and ulnar loop. However, there is only one delta. Therefore, it is appropriate to the category of a technical tented arch in the tented arch series of fingerprint patterns [1] (Figure 2). 
Figure 2.

In 1993, the FBI conducted a study on the frequency of fingerprint patterns. In that study, 17,951,192 individuals were included from the male population. The tented arch pattern appeared on the right little finger of 114,881 individuals. Therefore, it can be noted that Dr. King's display of the tented arch pattern on the right little finger is $0.639963073 \%$ of the total [2] which is six hundred thirty-nine million, nine hundred sixty-three thousand, seventy-three billionths (Figure 3).

\section{$114,881 \quad 0.639963073$ \\ -------- = ------- \\ $17,951,192 \quad 100$}

Figure 3: This is an unusual phenomenon in the study of dermatoglyphics.

We are looking at a tented arch pattern from the right little finger of Dr. MLK, Jr., which displays both a radial and ulnar loop formation in juxtaposition; this is another rare phenomenon with Dr. King's right little fingerprint. As radial and ulnar loops are in juxtaposition in the spectrum of fingerprint patterns, it is an impression in juxtaposition within its own display. I have often wondered if a tented arch pattern like the one that was on the right little finger of Dr. King resides midway between the radial and ulnar loop in the evolution of fingerprint patterns. In view of the fact that radial development precedes ulnar development for the hands, it is logical to assume that radial loops appeared on the human person prior to ulnar loops. The ulnar loop is therefore more recent and maintains the highest frequency of all patterns. As a result, ulnar loops are not likely to dissipate genetically in current time. In comparison, having a low frequency, the radial loop indicates a fading out of evolutionary existence.

In the display of this pattern, the loop formation on the left occupies a near vertical profile and is radial in appearance while the formation on the right is diagonal and ulnar. This is the fourth noted rarity of Dr. King's fingerprint. The fact that a radial loop formation was on the right little finger is a clear departure from the expected frequency of the dermal ridge arrangements [3] rarity number five (Figure 4). The frequency of the radial loop on the right little finger is $0.532 \%$.

\begin{tabular}{|l|}
\hline This is the frequency of the ulnar loop on the right little finger: \\
$14768305 \quad 82.269216439777369658794803152905$ \\
17951192 \\
\hline
\end{tabular}




\section{Conclusion}

Dr. Martin Luther King, Jr.'s right little fingerprint had a tented arch frequency of $0.639963073 \%$. As a frequency, it is less than $1 \%$. One percent is the first whole unit in the populous direction. Anything less than one percent is on the other side of the spectrum. A person as such may be able to see things in a different light [4].

\section{References}

1. (2006) FBI "Science of Fingerprints Classification and Uses". 74.

2. Andres J Washington (2000) Distribution of NCIC FPC Including 17,951,192 Males Retrieved.

3. Andres J Washington (2018) The Radial Loop Fingerprint Pattern". EC Psychology and Psychiatry 7.3.

4. Andres J Washington (2019) Scholars J Edu Humanit Lit 2(3): 133. 